DOI https://doi.org/10.46845/2541-8254-2021-2(29)-6-6

УДК 664.681 .2

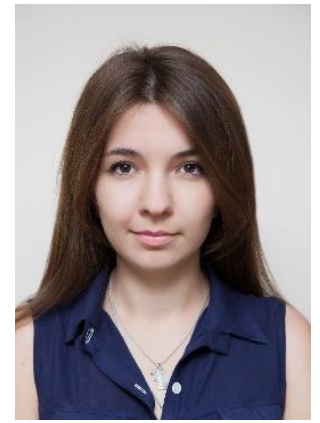

\title{
ИССЛЕДОВАНИЕ РЕОЛОГИЧЕСКИХ СВОЙСТВ БИСКВИТНОГО ТЕСТА НА ОСНОВЕ НЕХЛЕБОПЕКАРНЫХ ВИДОВ МУКИ С САХАРОЗАМЕНИТЕЛЕМ
}

\author{
Бедо Е.П., студентка 4-го курса, \\ e-mail: katerinabedo@gmail.com \\ ФГБОУ ВО «Калининградский государственный \\ технический университет» \\ Альшевская М.Н., канд. техн. наук, доц., \\ e-mail: marina.alshevskaya@klgtu.ru \\ ФГБОУ ВО «Калининградский государственный \\ технический университет» \\ Анистратова О.В., канд. техн. наук, \\ e-mail: anistratova1981@mail.ru \\ ФГБОУ ВО «Калининградский государственный \\ технический университет»
}

Для кондитерских изделий характерно высокое содержание сахара. В состав бисквитного теста кроме сахаров также входит пшеничная мука, однако белок, содержащийся в ее составе, может вызывать аллергические реакции у человека. Поэтому исследования по совершенствованию рецептур и технологий кондитерских изделий с использованием нехлебопекарных видов муки и сахарозаменителем актуальны. Целью данной работы стало изучение реологических свойств бисквитного теста с сахарозаменителем из амарантовой, овсяной муки и их смеси. Объект разработки - бисквит на основе нехлебопекарных видов муки с сахарозаменителем. Работа выполнена в Калининградском государственном техническом университете. На основании проведенных лабораторных исследований была изучена эффективная вязкость образцов бисквитного теста с добавлением эритрита и нехлебопекарных видов муки. Показаны уравнения зависимости эффективной вязкости. Установлено оптимальное соотношение овсяной и амарантовой муки в рецептуре бисквитного теста.

Ключевье слова: кондитерские изделия, бисквитное тесто, реологические свойства, глютен, эритрит, сахарозаменитель, подсластитель, овсяная мука, амарантовая мука

\section{ВВЕДЕНИЕ}

Сахарный диабет является алиментарно-зависимым заболеванием, связанным с наследственной предрасположенностью, или приобретенным вследствие различных негативных факторов, в том числе и сопряженных с потреблением продуктов, содержащих в своем составе легкоусвояемые углеводы и сахара. Свыше 350 млн. жителей планеты страдают сахарным диабетом 1- и 2-го типа, при этом имеется тенденция к трехкратному увеличению заболевших.

В качестве альтернативы сахару в питании людей, больных диабетом, возможно использование сахарозаменителей - низкокалорийных веществ, не повышающих уровень глюкозы в крови.

В настоящее время на предприятиях общественного питания производится широкий ассортимент изделий (тортов, пирожных, рулетов), основой изготовления которых является бисквитное тесто. 
Кондитерские изделия традиционного состава, где в качестве основного компонента выступает пшеничная мука, обладают большим количеством быстроусвояемых углеводов и высоким гликемическим индексом.

Ученые и производственники все большее внимание уделяют возможности частичной или полной замены пшеничной муки на ржаную, льняную, амарантовую или черёмуховую. В научной литературе есть данные о возможности замены пшеничной муки в бисквитных изделиях на гречневую, ржаную, соевую, овсяную [1]. Но во всех исследованиях для приготовления бисквитного полуфабриката используется сахар.

На рынке представлено большое разнообразие видов сахарозаменителя. Было изучено влияние эритрита, стевии и комбинированного подсластителя сукралозы на пенообразующую способность меланжа, а также на органолептические и физические показатели качества готовых бисквитных полуфабрикатов. Наилучшими показателями обладал бисквитный полуфабрикат с добавлением эритрита [2]. Это и обусловило выбор данного сахарозаменителя для дальнейших исследований.

Любые изменения в рецептуре бисквитов требуют тщательного анализа, поскольку нужно заменить традиционные для бисквитного полуфабриката виды сырья (пшеничную муку и сахар). В связи с этим важно изучение реологических свойств теста (вязкости), так как они находятся в тесной зависимости от внутренней структуры вещества. По мнению академика А. В. Горбатова, эффективная вязкость является итоговой характеристикой, описывающей равновесное состояние между процессами восстановления и разрушения структуры [2].

\section{ЦЕЛИ И ЗАДАЧИ ИССЛЕДОВАНИЯ}

Целью работы являлось: изучить реологические свойства бисквитного теста с сахарозаменителем из амарантовой, овсяной муки и их смеси.

Для решения поставленной цели необходимо было решить следующую задачу:

- изучить динамику изменения эффективной вязкости в зависимости от скорости сдвига в бисквитном тесте из амарантовой, овсяной муки и их смеси с эритритом.

\section{ОБЪЕКТ ИССЛЕДОВАНИЯ}

Для приготовления образцов использовалось сырье, по качеству соответствующее требованиям нормативной и технической документации (табл. 1).

Таблица 1 - Основное и вспомогательное сырье

\begin{tabular}{|c|c|}
\hline Компонент & Нормативная документация \\
\hline Мука пшеничная высшего сорта & ГОСТ Р 52189-2003, ТР ТС 021/2011, ТР ТС 022/2011 \\
\hline Мука амарантовая & $\begin{array}{l}\text { ТУ } 10.61 .22-026-66032220-2014, \text { ТP ТC } 021 / 2011 \text {, ТP } \\
\text { TC 022/2011 }\end{array}$ \\
\hline Мука овсяная & ГОСТ 3034-75, ТР ТС 021/2011, ТР ТС 022/2011 \\
\hline Caxap & ГОСТ $33222-2015$, ТР ТС 029/2011 \\
\hline Эритрит & ТУ 10.89.19-009-17274463-2018, ТР ТС 029/2012 \\
\hline Меланж & ГОСТ $31654-2012$, ТР ТС $021 / 2011$ \\
\hline
\end{tabular}

\section{МЕТОДЫ ИССЛЕДОВАНИЯ}

Для изучения влияния сахарозаменителя эритрита и амарантовой, овсяной муки и их смеси на вязкость теста были приготовлены:

- два образца бисквитного теста с пшеничной мукой с добавлением сахара и сахарозаменителя (контроль № 1 и 2);

- четыре образца бисквитного теста с овсяной мукой, массовая доля муки в образцах $20 ; 24 ; 28$ и $32 \%$ (образцы $1.1-1.4$ ); 
- $\quad$ четыре образца бисквитного теста с амарантовой мукой, массовая доля муки в образцах $15 ; 17 ; 19$ и $21 \%$ (образцы $2.1-2.4$ );

- образец бисквитного теста со смесью амарантовой и овсяной муки, массовая доля овсяной муки $8 ; 12$ и $16 \%$ амарантовой муки $15 \%$. Массовая доля эритрита во всех образцах $20 \%$ (табл. 2).

Таблица 2 - Рецептуры образцов бисквитного теста

\begin{tabular}{|c|c|c|c|c|c|c|c|c|c|c|c|c|c|}
\hline \multirow[b]{2}{*}{$\begin{array}{c}\text { Наименова- } \\
\text { ние сырья }\end{array}$} & \multicolumn{13}{|c|}{ Наименование образцов } \\
\hline & $\begin{array}{l}\vec{a} \\
\hat{B} \\
0 \\
0 \\
0 \\
0 \\
0 \\
0\end{array}$ & 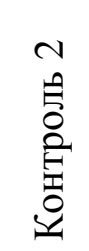 & 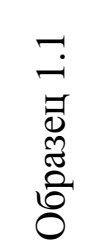 & 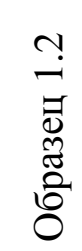 & 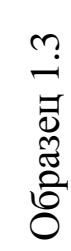 & $\begin{array}{l}\stackrel{+}{.} \\
\overrightarrow{0} \\
\tilde{\Xi} \\
\widetilde{0} \\
0 \\
0\end{array}$ & 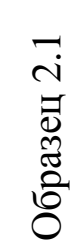 & 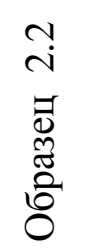 & 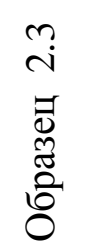 & 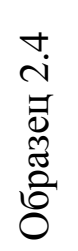 & 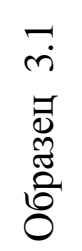 & 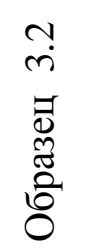 & 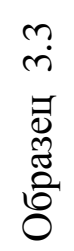 \\
\hline $\begin{array}{ll}\text { Мука } & \text { пше- } \\
\text { ничная }\end{array}$ & 29,5 & 33 & - & - & - & - & - & - & - & - & - & - & - \\
\hline Мука овсяная & - & - & 20 & 24 & 28 & 32 & - & - & - & - & 8 & 12 & 16 \\
\hline $\begin{array}{l}\text { Мука амаран- } \\
\text { товая }\end{array}$ & - & - & - & - & - & - & 15 & 17 & 19 & 21 & 15 & 15 & 15 \\
\hline Caxap & 29,5 & - & - & - & - & - & - & - & - & - & - & - & - \\
\hline Эритрит & - & 20 & 20 & 20 & 20 & 20 & 20 & 20 & 20 & 20 & 20 & 20 & 20 \\
\hline Меланж & 41 & 47 & 60 & 56 & 52 & 48 & 65 & 63 & 61 & 59 & 57 & 53 & 49 \\
\hline Macca, $\Gamma$ & 100 & 100 & 100 & 100 & 100 & 100 & 100 & 100 & 100 & 100 & 100 & 100 & 100 \\
\hline
\end{tabular}

Для приготовления бисквитного теста взбивали меланж с сахаром (или эритритом) до получения устойчивой пены, затем вводили муку. Тесто выпекали в форме диаметром 140 мм при $180{ }^{\circ} \mathrm{C} 18-25$ мин.

В полученных образцах бисквитного теста определяли вязкость при помощи ротационного вискозиметра Brookfield DV-II + Pro с использованием шпинделя RV-6, температура образцов теста $21 \pm 1{ }^{0} \mathrm{C}$.

\section{РЕЗУЛЬТАТЫ ИССЛЕДОВАНИЙ}

Бисквитное тесто по своим реологическим свойствам относится к структурированным неньютоновским системам, которые от пшеничного теста отличаются повышенной вязкостью.

Кривые течения бисквитного теста при комнатной температуре и градиенте скорости от 0 до $100 \mathrm{c}^{-1}$ можно описать степенным уравнением Оствальда-Де Виля [2].

В ходе проведенного эксперимента устанавливалось изменение реологических свойств бисквитных полуфабрикатов при разном соотношении рецептурных компонентов по изменению их эффективной вязкости в зависимости от градиента скорости сдвига (рисунок).

Анализ экспериментальных данных показал, что исследуемые образцы имеют незначительные отличия показателя вязкости с увеличением скорости сдвига, разнясь лишь значениями эффективной вязкости при небольших скоростях. 


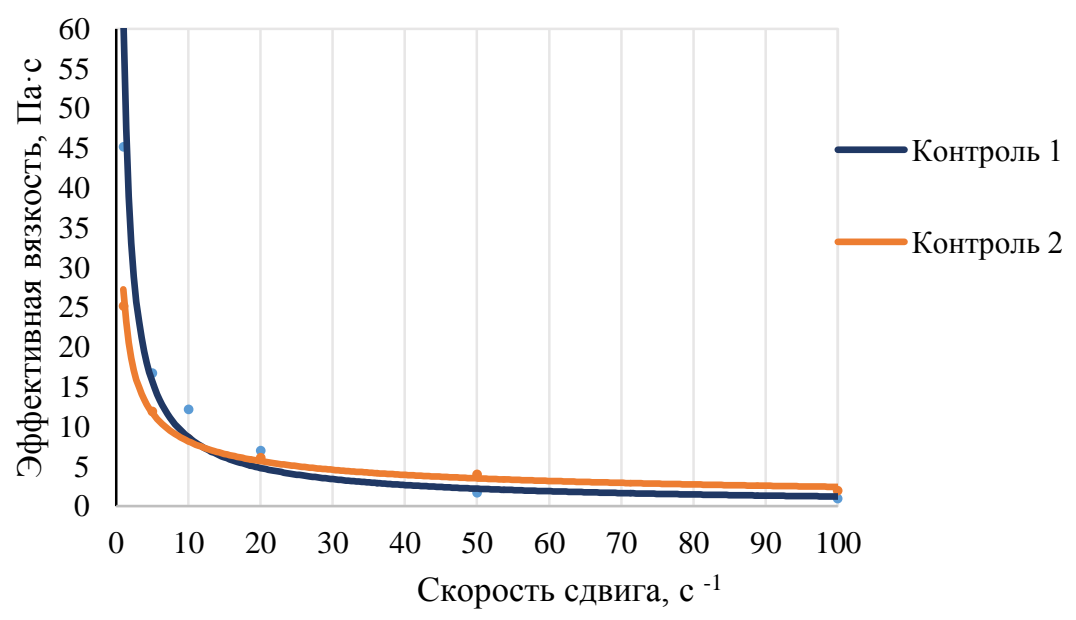

a)

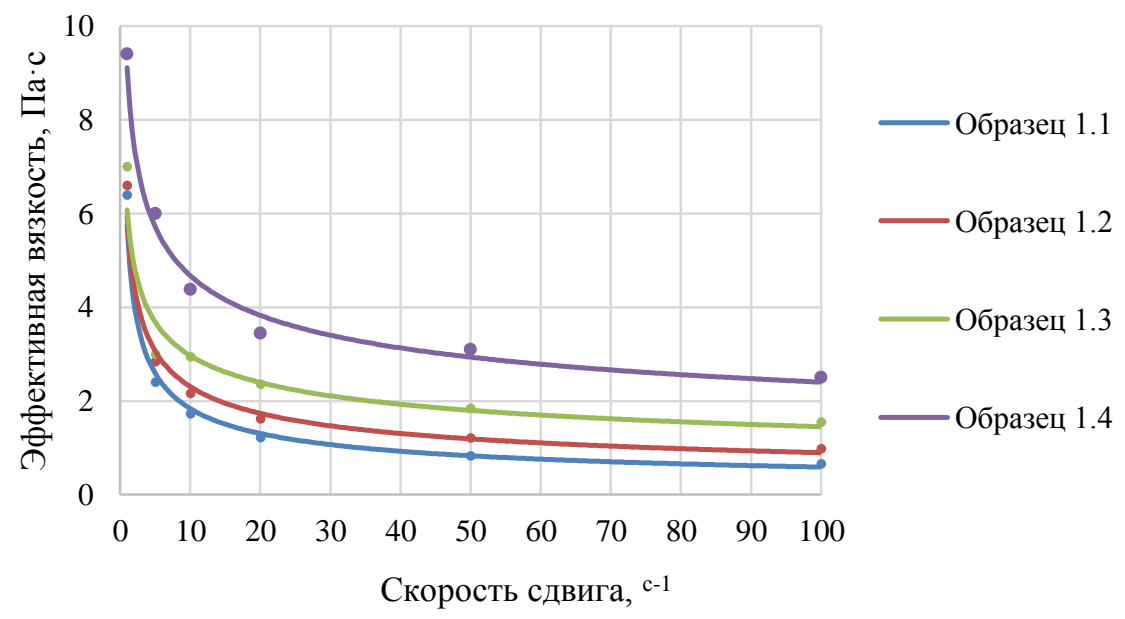

б)

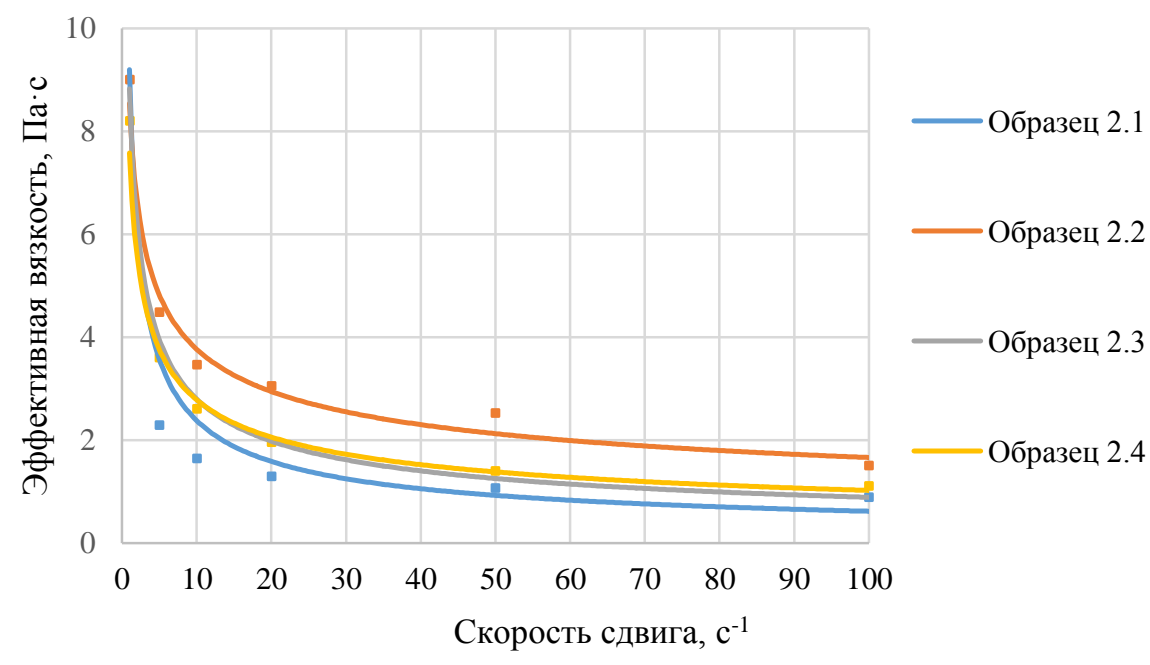

B)

Рисунок. Изменение эффективной вязкости образцов бисквитного теста: a - образцы с пшеничной мукой; б - образцы с овсяной мукой; в - образцы с амарантовой мукой; г - образцы с добавлением смеси овсяной и амарантовой муки 


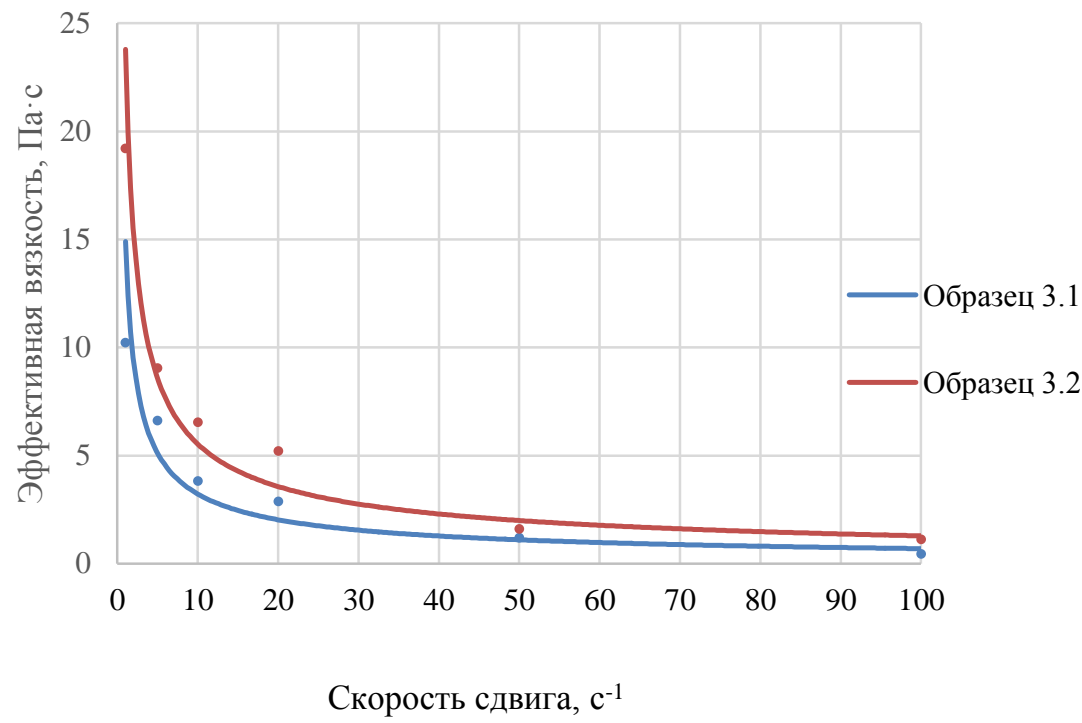

г)

Рисунок. Окончание

Все исследуемые образцы бисквитного теста характеризуются повышением вязкости при небольших скоростях деформации; с увеличением скорости сдвига вязкость уменьшается, указывая на то, что исследуемые образцы относятся к псевдопластичным жидкостям. Было отмечено, что вязкость значительно, лавинообразно уменьшалась при скорости сдвига до $50 \mathrm{c}^{-1}$, далее данный показатель изменялся незначительно. Такое уменьшение вязкости псевдопластических систем может быть объяснено разрушением структурной сетки и агрегатов частиц с ориентацией последних вдоль вектора скорости [3]. Наибольшее значение начальной вязкости имел Контроль, наименьшее - Образец 1.1.

Образец 3.3 с содержанием 16 \% овсяной и $15 \%$ амарантовой муки был исключен из испытаний, поскольку обладал излишне вязкой консистенцией, и при измерении помощи ротационного вискозиметра Brookfield DV-II + Pro с использованием шпинделя RV-6 показания прибора выдавали ошибку.

В ходе обработки данных было установлено, что полученные зависимости достаточно хорошо описываются степенной (гиперболической) функцией, при этом величины достоверности аппроксимации приближены к 1. Регрессионные зависимости изменения эффективной вязкости образцов бисквитного теста в зависимости от соотношения овсяной, амарантовой муки приведены в табл. 3.

Скорость разрушения структуры определяется как первая производная от изменения эффективной вязкости изучаемых образцов бисквитного теста. Показатели степени в уравнениях, указанных в табл. 3, характеризуют темп разрушения структуры.

Из таблицы видно, что наибольшим темпом разрушения структуры обладает в сравнении с контрольным образцом (Контроль 2) Образец 1.4, а наименьшим - образец 3.2, при этом темп разрушения структуры остальных образцов остается на уровне 0,311-0,588. 
Таблица 3 - Уравнения зависимости эффективной вязкости образцов бисквитного теста от градиента скорости сдвига

\begin{tabular}{|c|c|c|c|c|}
\hline $\begin{array}{c}\text { Исследуемый } \\
\text { объект }\end{array}$ & Уравнение & $\begin{array}{l}\text { Коэффициент } \\
\text { детерминации }\end{array}$ & $\begin{array}{c}\text { Уравнение скорости } \\
\text { разрушения }\end{array}$ & $\begin{array}{c}\text { Темп разрушения } \\
\text { структуры }\end{array}$ \\
\hline Контроль 1 & $y=61,607 \cdot x^{-0,851}$ & $\mathrm{R}^{2}=0,9544$ & $y=-52,427557 \cdot x^{-1,851}$ & 0,851 \\
\hline Образец 1.1 & $y=5,7471 \cdot x^{-0,495}$ & $\mathrm{R}^{2}=0,9887$ & $y=-2,8448 \cdot x^{-1,495}$ & 0,495 \\
\hline Образец 1.2 & $y=5,9494 \cdot x^{-0,411}$ & $\mathrm{R}^{2}=0,9854$ & $y=-2,4452 \cdot x^{-1,411}$ & 0,411 \\
\hline Образец 1.3 & $y=6,0834 \cdot x^{-0,311}$ & $\mathrm{R}^{2}=0,9519$ & $y=-1,8919 \cdot x^{-1,311}$ & 0,311 \\
\hline Образец 1.4 & $\mathrm{y}=9,1138 \cdot \mathrm{x}^{-0,29}$ & $\mathrm{R}^{2}=0,98$ & $y=-2,643 \cdot x^{-1,29}$ & 0,290 \\
\hline Контроль 2 & $y=27,275 \cdot x^{-0,524}$ & $\mathrm{R}^{2}=0,9818$ & $y=-14,2921 \cdot x^{-1,524}$ & 0,524 \\
\hline Образец 2.1 & $y=9,2026 \cdot x^{-0,588}$ & $\mathrm{R}^{2}=0,8546$ & $y=-5,4111 \cdot x^{-1,588}$ & 0,588 \\
\hline Образец 2.2 & $y=8,5474 \cdot x^{-0,356}$ & $\mathrm{R}^{2}=0,9688$ & $y=-3,0523 \cdot x^{-1,356}$ & 0,356 \\
\hline Образец 2.3 & $y=8,8287 \cdot x^{-0,499}$ & $\mathrm{R}^{2}=0,9999$ & $y=-4,4055 \cdot x^{-1,499}$ & 0,499 \\
\hline Образец 2.4 & $y=7,5778 \cdot x^{-0,435}$ & $\mathrm{R}^{2}=0,9919$ & $y=-3,2963 \cdot x^{-1,435}$ & 0,435 \\
\hline Образец 3.1 & $y=19,561 \cdot x^{-0,577}$ & $\mathrm{R}^{2}=0,9098$ & $y=-11,2867 \cdot x^{-1,577}$ & 0,577 \\
\hline Образец 3.2 & $y=14,912 \cdot x^{-0,665}$ & $\mathrm{R}^{2}=0,9142$ & $y=-9,9165 \cdot x^{-1,665}$ & 0,665 \\
\hline
\end{tabular}

\section{ЗАКЛЮЧЕНИЕ}

В ходе проведенных исследований была изучена эффективная вязкость образцов бисквитного теста с добавлением эритрита и нехлебопекарных видов муки (овсяной, амарантовой и их смеси). Показаны уравнения зависимости эффективной вязкости образцов бисквитного теста от градиента скорости сдвига, и определены темпы разрушения структуры.

Установлено оптимальное соотношение овсяной и амарантовой муки в рецептуре бисквитного теста (12\% овсяной и 15 \% амарантовой муки от общей массы теста).

Таким образом, используя смеси из овсяной и амарантовой муки, можно регулировать значения вязкости бисквитного теста, изменяя соотношения данных видов муки в смесях при производстве бисквитных полуфабрикатов для профилактического питания.

\section{СПИСОК ЛИТЕРАТУРЫ}

1. Алексеев, Г.В. Исследование структурно-механических свойств бездрожжевого бисквитного теста на основе полножирной муки из семян льна / Г.В. Алексеев, В.Н. Красильников, М.С. Киреева // ВЕСТНИК МАХ. - 2014. - № 2. - С. 69-73.

2. Альшевская, М.Н. Обоснование рецептуры бисквита с использованием сахарозаменителей / М.Н. Альшевская, Е.П. Бедо // Технологии и продукты здорового питания: XII Национальная научно-практическая конференция с международным участием: сборник статей. - Саратов: Саратовский государственный аграрный университет им. Н.И. Вавилова, 2021. - C. 33-37.

3. Горбатов, А.В. Реология мясных и молочных продуктов / А.В. Горбатов. Москва: Пищевая промышленность, 1979. - 384 с.

4. Крупенникова, В.Е. Определение динамической вязкости на ротационном вискозиметре Brookfield RVDVII+Pro / В.Е. Крупенникова, В.Д. Раднаева., Б.Б. Танганов. - УланУдэ: Изд-во ВСГТУ, 2011. - 48 с. 
5. Лаврова, Л.Ю. Использование нетрадиционных видов муки в производстве бездрожжевых кексов / Л.Ю. Лаврова, А.Н. Лесникова, А.И. Балакина // Хлебопродукты. 2018. - № 6. - С. 58-60.

6. Муратова, Е. И. Реология кондитерских масс : монография / Е. И. Муратова, П. М. Смолихина. - Тамбов : Изд-во ФГБОУ ВПО «ТГТУ», 2013. - 188 с.

7. Макарова, О.В. Свойства бисквитных полуфабрикатов на основе муки из продуктов переработки гречки / О.В. Макарова, Е.Г. Иоргачева, Е.Н. Котузаки. - Одесса: Одесская национальная академия пищевых технологий, 2009. - С. 47-50.

\title{
STUDY OF RHEOLOGICAL PROPERTIES BISCUIT DOUGH BASED ON NON-BAKING FLOURS WITH SWEETENER
}

\author{
E.P. Bedo, student \\ e-mail: katerinabedo@gmail.com \\ Kaliningrad State Technical University \\ M.N. Alshevskaya, PhD, Associate Professor \\ e-mail: marina.alshevskaya@klgtu.ru \\ Kaliningrad State Technical University \\ O.V. Anistratova PhD, Associate Professor \\ e-mail: anistratova1981@mail.ru \\ Kaliningrad State Technical University
}

Confectionery products are characterized by a high sugar content. The composition of the sponge dough, in addition to sugars, also includes wheat flour, but the protein contained in its composition can cause allergic reactions in humans. Therefore, research on improving the recipes and technologies of confectionery products, with the replacement of sugar with the use of non-bakery types of flour is relevant. The aim of this work was to study the rheological properties of sponge dough with sweetener from amaranth, oat flour and their mixture. Objects of development - a sponge cake based on non-baking types of flour with sweetener. The work was performed at the Kaliningrad State Technical University. On the basis of laboratory studies, the effective viscosity of sponge dough samples with the addition of erythritol and non-baking types of flour was studied. The equations of the dependence of the effective viscosity are shown. The optimal ratio of oatmeal and amaranth flour in the recipe of sponge dough is established.

Keywords: confectionery, biscuit dough, rheological properties, gluten, erythritol, sweetener, sweetener, oat flour, amaranth flour. 